\title{
On the Lewisian Principle of Recombination and Quidditism
}

\section{Karol Lenart ${ }^{1}$ (D)}

Received: 13 March 2020 / Accepted: 10 November 2020 / Published online: 24 November 2020

(C) The Author(s) 2020, corrected publication 2021

\begin{abstract}
In this paper, I discuss a connection between quidditism and the Lewisian principle of recombination. I begin by reconstructing a typical characterisation of a Lewisian principle of recombination, followed by an explanation of quidditism. In the remainder, I argue that a proponent of a Lewisian principle of recombination cannot endorse quidditism without some important modifications of her view.
\end{abstract}

Keywords Recombination · Quidditism · Lewis · Properties · Individuation · Possible worlds

\section{Preliminaries}

Following Efird and Stoneham (2008), I distinguish between the question about what possibilities are (i.e., What is their nature?) from a question about what possibilities there are (i.e., What possibilities exist?). In response to the first question, actualists usually say that possibilities are abstract entities (Plantinga 1976, Adams 1981) or fictions (Armstrong 1989). In turn, possibilists (also known as modal realists) claim that possibilities are concrete entities (Lewis 1986, McDaniel 2004). In contrast, the second question concerns what is possible; for example, whether there are haecceitistic possibilities for individual objects, such as the possibility of me being a poached egg, or whether there are possibilities involving alien individuals or properties (where an entity is considered alien if it cannot be given by a recombination of actual entities). This paper focuses solely on the second question.

There are different ways to determine what possibilities exist. One available option is to claim that possibilities are governed by essences. For example, by accepting the essentiality of origins or natural kind essentialism, one might constrain what possibilities there are. Another option is to appeal to science and argue that there are

Karol Lenart

karol.lenart@doctoral.uj.edu.pl

1 Department of Philosophy, Jagiellonian University, ul. Grodzka 52, 33-332 Krakow, Poland 
nomological restrictions imposed on possibilities, and yet another option is to appeal to logical consistency and claim there are no inconsistent (i.e., contradictory) possibilities. In this paper, I focus on a different way of answering the question about what possibilities there are; namely, on the principle of recombination (henceforth, PR), specifically a variant proposed by David Lewis. The distinctiveness of such an approach is its principled and systematic explanation of possibilities. In other words, PR leaves no gaps in logical space, because every way, some possible world $W$ (or part of $W$ ) could have been is a way that some other possible world $W^{*}$ or part of $W^{*}$ actually is (Lewis 1986: p. 86). PR differs from all three mentioned strategies in some important ways. Firstly, it is a purely metaphysical principle that answers the question of what possibilities exist, in an objective way that does not rely on modal intuitions (e.g., ones concerning what is essential or accidental). Secondly, in contrast to the strategy of following scientific results, PR does not depend on scientific findings. It is an a priori rather than a posteriori principle. Thirdly, in contrast to the consistency strategy, a (Lewisian) characterisation of PR does not involve any modal notions; thus, it avoids circularity usually ascribed to consistency strategies. ${ }^{1}$

Of the different variants of PR discussed in the literature, the most notable alternative to the Lewisian variant is one endorsed by Armstrong (1989). According to Armstrong, PR applies to intensional entities, such as universals, and its characterisation involves modal notions, such as consistency. For example, some set $S$ of universals is consistent if it is not possible for it to contain an element $e$ and its negation $r e$. Thus, it is a non-reductive explanation of modality. That said, a main difference between the Lewisian and the Armstrongian variants of PR lies in the fact that PR for Armstrong is a principle explaining the metaphysical nature of possible worlds; namely, that they are a fictional recombinations of actual, existing things. For Lewis, however, PR tells us nothing about what possible worlds are. Instead, it is a principle explaining how many possible worlds there are.

Since I focus in this paper only on the question about what possibilities exist, I discuss the Lewisian variant of PR exclusively. More specifically, I am interested in how Lewisian PR relates to quidditism, a view stating there are qualitatively indiscernible possible worlds differing only in the distribution of the identities of properties. For Lewis (and his followers), maintaining PR and quidditism is valuable because both are necessary for establishing the so-called Ramseyan humility, a sceptical view about the knowability of the identities of properties. However, I argue that a proponent of Lewisian PR cannot endorse quidditism without modifying some basic assumptions of Lewisian metaphysics; for example, giving up Humean supervenience.

The structure of this article is as follows: In section 2, I present Lewisian PR in more detail. In section 3, I explain what quidditism is and present initial thoughts on the relationship between Lewisian PR and quidditism. In section 4, I reconstruct how Curtis (2016) argues a proponent of Lewisian PR can extend the principle to properties and endorse quidditism without modifying any basic assumptions of Lewisian metaphysics. In section 5, I provide several reasons why Curtis's solution fails. I conclude that, in order to endorse quidditism, a proponent of Lewisian PR must either revise her metaphysical postulates (e.g., give up Humean supervenience) or give up quidditism.

\footnotetext{
${ }^{1}$ The last point holds only as long as we do not impose any restrictions on PR that might invoke primitive modality.
} 


\section{Characterising PR}

David Lewis characterised PR very briefly and in general terms. Consequently, contemporary researchers lack consensus on how to properly formulate Lewisian PR. Some recent commentaries on Lewis's works (Darby \& Watson 2010, Efird \& Stoneham 2008) include sophisticated characterisations of PR meant to address issues affecting Lewis's original formulation. In this paper, however, I am not interested in deciding the best way of characterising Lewisian PR. For the purpose of this analysis, it will be sufficient to use the simplified account provided by Divers and Melia (2002) and Wilson (2015). In fact, no matter how we decide to characterise Lewisian PR, if it is correct about principles governing possibilities, the issue of quidditism will inevitably manifest itself.

In On the Plurality of Worlds, Lewis appeals to Hume's Dictum (HD) to explicate what PR is. According to $\mathrm{HD}$, there are no necessary connections between wholly distinct and intrinsically characterised entities (Wilson 2010: p. 604). ${ }^{2}$ Lewis then applies HD to possible entities and treats it as a principled answer to the question of how logical space is constructed. It is important to note, however, that PR is not a world-making principle (as it is in case of Armstrong's combinatorialism). Instead, it is a principle satisfied by a plurality of worlds that are ontologically independent from it (Roca-Royes 2018: p. 7). In other words, possible worlds are not constructed by PR, but governed by it.

PR identified with HD entails a radical contingentism according to which anything could or could not coexist with anything else. Intuitively speaking, one could patch together parts from different possible worlds to generate a new possible world. Most importantly, as Lewis observes, "how much this means depends on what we take the distinct elements to be" (Lewis 2009: p. 209). They could be individuals, understood as concrete, spatio-temporal parts of worlds, or abstract parts, such as fundamental properties.

But let me characterise PR more precisely. Since I am discussing PR from the perspective of Lewis's theory, it seems that in order to make PR consistent with some basic metaphysical postulates of Lewisian modal realism, qualifying PR a bit more is necessary. Those interested in PR have indicated a plausible variant of PR consistent with some basic assumptions of modal realism that could be stated as follows:

For any number of individuals $x_{1}, x_{2} \ldots x_{n}$ there is a world containing any number of duplicates of each, if there is spacetime big enough to hold them all, and such that for any spatio-temporal relation the duplicates in question stand in that relation. (Divers and Melia 2002, Wilson 2015)

Here we can identify three important qualifications of Lewisian PR. Firstly, in order to avoid a commitment to the transworld identity of individuals (which is precluded by Lewisian modal realism), PR has to be defined as a principle concerning duplicates of individuals rather than transworld individuals, where something is a transworld individual if it exists across distinct possible worlds. The reason for defining PR in terms of

\footnotetext{
${ }^{2}$ A restriction to intrinsically characterised entities is added to ensure that HD is about entities considered in themselves, i.e., not in any relation to other entities.
} 
duplicates is that if anything can coexist or fail to coexist with anything else, then some actual individual $a$ might coexist with some non-actual individual $b$ at non-actual possible world $W$. As a result, given unqualified PR, individual $a$ from $W_{@}$ would be (transworld) identical to $b$ at $W$. Given that the transworld identity of individuals is denied by Lewis (which follows from his argument from accidental intrinsics: Lewis 1986: p. 201), PR has to preclude transworld identities for individuals as well.

The second qualification states that every possible world can contain as many duplicates as the size of its space-time permits. In other words, there needs to be a space-time large enough to hold all the duplicates together. For example, if there is a continuum of points in space-time, then there can only be a continuum with that many duplicates in such a space-time, for at given point of space-time there can only be one individual object. The latter point is motivated by a fact that PR applies to wholly distinct and intrinsically characterised entities. Thus, it is not applicable to wholly or partially overlapping entities that share all or part of their intrinsic features.

The third qualification states that every kind of spatio-temporal relation between relevant duplicates indicates a distinct possibility. Without such a postulate, PR would struggle with generating possibilities about arrangements of duplicates within a single possible world, and such arrangements are necessary grounds for possibilities for ordinary macro-objects. As Divers and Melia indicate:

[Lewis's stated] principle of recombination is insufficient to generate worlds where donkeys talk or where there are blue swans. Grant that there is a set of actual particles such that were those particles arranged in a certain way they would constitute a talking donkey. It is not enough for a world to represent that possibility that it should contain a duplicate of each such particle, for obviously such particles could exist, scattered to the corners of the universe, without constituting a talking donkey. (2002: p. 16)

Let me reconstruct Divers and Melia's argument. For the sake of argument, assume (as Lewis did) that Humean supervenience is true. According to Humean supervenience, there is only a distribution of local (Humean) qualities across points of space-time at the fundamental level of the world, and everything else (including the identities or properties of macro-objects, such as animals or poker chips) supervenes on it. Following that, suppose our actual world, call it $W_{@}$, has a distribution $D$ of local qualities (e.g., particles, if we assume that contemporary physics adequately describes what is fundamental) which precludes existence of talking donkeys in $W_{@}$. Yet it seems possible that there might be talking donkeys. In order to explain such possibility, a proponent of Lewisian PR might claim that we could recombine fundamental qualities from $W_{@}$ by postulating a possible world $W$ that would contain duplicates of fundamental qualities of $W_{@}$ and which could be recombined to give rise (via Humean supervenience) to a talking donkey. However, the mere recombination of the duplicates of fundamental qualities would not provide necessary conditions for the possibility of some donkey talking since it is possible that the recombined fundamental qualities would be unrelated and scattered away across the galaxies of relevant possible worlds. Of course, it might accidentally happen that a mere recombination would result, at some point after extensive iteration, in a distribution of fundamental qualities that would give rise to a talking donkey. However, contrary to our initial condition imposed 
on Lewisian PR, such a variant of PR would no longer be a principled way of obtaining all possibilities. Thus, it seems that mere duplication is not enough to generate all genuine possibilities. What is needed to explain (in a principled way) a possibility of a talking donkey is to postulate that duplicates of fundamental qualities have to stay in some spatio-temporal (or analogically spatio-temporal) relation that ties them together. Only under this additional constraint on PR can we guarantee that the recombination of the duplicates of fundamental qualities gives rise to a relevant possibility.

Having introduced basic assumptions associated with Lewisian PR, let me now describe its connection to quidditism and investigate whether both views are compatible. Before I tackle this issue directly, let me briefly explain what it takes to be quidditist in general.

\section{Varieties of Quidditism}

Quidditism resists a general definition because many people mean different things by it. According to Lewis (2009: p. 209), quidditism is to properties as haecceitism is to individuals. But what is haecceitism to individuals? For Lewis, haecceitism allows for any two qualitatively indiscernible possible worlds to be numerically distinct; that is, according to haecceitism, there are possible worlds that have the same qualitative representation (or qualitative character) but nevertheless differ in what they represent de re (non-qualitatively) concerning some particular individuals (Lewis 1986: p. 221). Analogically, quidditism is a view that for any two possible worlds that are structurally indiscernible, they can be numerically distinct; that is, according to quidditism, there are possible worlds that have the same structure but differ in which property occupies which property role. A property role is a complete qualitative ${ }^{3}$ characterisation of a given property, including (most importantly) its causal powers and nomological roles, whereas structurally indiscernible worlds are those that exhibit exactly the same distribution of property roles. Since such worlds share the same causal structure and laws of nature, they are observationally indiscernible for us. Speaking very roughly, we could say that at any pair of structurally indiscernible worlds, the same things happen.

With this in mind, we could formulate quidditism as follows: For any fundamental properties ${ }^{4} F$ and $G$, and for any property roles $R$ and $S$, if $F$ plays role $R$, and if $G$ plays role $S$, it is possible for $F$ and $G$ to swap their respective property roles. In effect, one receives a possibility according to which $G$ satisfies $R$, and $F$ satisfies $S$. Quidditism states that even though such possibilities have the same patterns as the distribution of property roles, they differ on which properties occupy each property role. Thus, they are distinct possibilities.

It seems that we have two different theses here that give rise to two different understandings of quidditism: one concerning differences between possible worlds,

\footnotetext{
${ }^{3}$ I rely on a notion of the qualitative features according to which a property is qualitative if its exemplification - that is, a fact that some $x$ has a qualitative property $F$-does not depend on what particular object $x$ is or on a relation $x$ bears with other objects and their relevant properties. Such criterion of qualitative properties is discussed by Adams (1979: p. 7) and Kment (2012: p. 574).

${ }^{4}$ There is a consensus about restricting a discussion of quidditism to fundamental properties. A main reason for that is that many non-fundamental properties (e.g., being red, being distinct from Eiffel Tower, or being Socrates) either lack easily identifiable causal powers or nomological roles.
} 
and a second one concerning property individuation. Such a division within quidditism has been recently highlighted by Smith (2016). Following his remarks, let me call the first form of quidditism recombinatorial quidditism (R-quidditism), according to which there are structurally indiscernible worlds differing solely in the permutation of properties, that is, in facts about which properties occupy which property roles. ${ }^{5}$

In contrast to R-quidditism, individuation quidditism (I-quidditism) is usually understood (Black 2000, Schaffer 2005, Locke 2012, Smith 2016) as a thesis about property individuation, according to which properties are individuated not by their respective property roles (including their causal, nomological, and other qualitative characteristics), but rather by their quiddities, unique natures which are irreducible to property roles. I-quidditism so understood is a denial of structuralism about properties, a view according to which the identities of properties are explained by their respective property roles. $^{6}$

However, there is no consensus among I-quidditists about the proper metaphysical status of quiddities. That said, what seems to be a common theme in all accounts of quiddities is that they are unique ${ }^{7}$ for their bearers and that they are irreducible to features included in property roles. In light of this, there are at least three possible metaphysical accounts of quiddities:

(1) A first option is to conceive them as non-qualitative, individual essences understood as unique (unshareable), non-qualitative properties, such as being identical with a property $F$ or just being $F$. Since such properties are ontologically grounded in the existence of their bearers, this metaphysical interpretation of quiddities seems to be equivalent to a view that properties are just numerically distinct.

(2) A second option is to treat non-qualitative individual essences as additional elements of properties that are not properties but belong to a distinct ontological category of being. Here one could make an analogy to bare particulars or Scotistic haecceities in order to explicate an ontological status of quiddities.

(3) A third option is to identify quiddities with qualitative (individual or general) essences that, despite being qualitative, are not included in their qualitative property roles. According to this view, a given property has its property role necessarily, and it has it in virtue of having a qualitative individual (or general) essence.

I argue that R-quidditism requires some form of I-quidditism to be true. If it is possible for properties to be freely recombined with their property roles, such a possibility has to be grounded in some account of how properties are individuated. In other words, what is possible for properties has to be grounded in some account of what properties are at the most fundamental level. This is justified by the fact that a principle of individuation of a given entity is necessary for it. If $P$ individuates some entity $e$, then in every

\footnotetext{
${ }_{5}^{5}$ For a further discussion of R-quidditism, see Schaffer (2005), Lewis (2009), and Smith (2016).

${ }^{6}$ For an overview of such argument see Locke (2012). On structuralism, see Shoemaker (1980), Hawthorne (2001), and Wang (2016).

${ }^{7} \mathrm{We}$ can define the uniqueness of quiddities in a following way: Uniqueness of quiddity $=$ def. For any quiddity, for any property $F$, and any property $G$, if $F(Q)$, then for any property $G$ distinct from $F$, it is necessary that it is not the case that $G(Q)$.
} 
possible world in which $e$ exists, $e$ is individuated by $P$. More specifically, if properties are individuated by their quiddities, then in every possible world in which properties exist, they are individuated by quiddities. If we add, following I-quidditism, that properties are only contingently tied to their property roles, then properties are contingently tied to their property roles in every possible world where properties exist. As a result, if properties are individuated by their quiddities, we can freely recombine properties with their property roles. Thus, truth of I-quidditism is a necessary condition for establishing R-quidditism. To put this in more general terms, the modal features of properties are grounded in non-modal features of properties that explain what they fundamentally are. ${ }^{8}$

That said, it seems that even though I-quidditism seems to be necessary for Rquidditism, it is not sufficient for it. ${ }^{9}$ The reason is that I-quidditism alone cannot provide a plurality of worlds required to formulate R-quidditism. I-quidditism is the non-modal view about the identities of properties, and because of that, in principle, it is consistent with a view that the only possible world is the actual world. However, Rquidditism requires the existence of possible worlds distinct from the actual world; otherwise, we would be unable to express quidditistic differences between distinct possible worlds. Thus, in order formulate R-quidditism, a proponent of I-quidditism has to supplement her view by a view generating required plurality of worlds. In order to achieve that, a Lewisian might appeal to PR, which allows for the recombination of elements of the actual world and the extension the logical space. ${ }^{10}$

As a result, a Lewisian can postulate the existence of structurally indiscernible possible worlds that differ with respect to the permutation of properties (which equals endorsing R-quidditism) only if (a) there are enough possible worlds in the logical space and (b) properties are not individuated by their property roles. The former condition is met by a postulate of Lewisian PR, while the later one by endorsement of Iquidditism.

However, is the Lewisian allowed to endorse all three views at once? In order to formulate R-quidditism within a Lewisian framework, it is necessary to extend PR to apply to properties and their property roles. However, there is a prima facie difficulty with such an extension of PR. In the next section, I reconstruct Curtis's argument for how a Lewisian could address this difficulty. Subsequently, I shall argue that his solution fails. Moreover, I argue that since proponents of the Lewisian framework are not interested in the individuation of properties and ignore I-quidditism, there is a second reason why endorsing R-quidditism might be hard for a Lewisian.

\section{How to Extend Lewisian PR to Properties}

In order to formulate R-quidditism within a Lewisian framework, one is required to accept PR. This holds because we can get quidditistic possibilities only under the

\footnotetext{
${ }^{8}$ For further elaboration of these arguments, see section 5.3 of this article.

${ }^{9}$ A similar point is made by Smith (2016: p. 241).

${ }^{10}$ Of course, the I-quidditist could appeal to some alternative principles governing logical space (e.g., the three mentioned in section 1 of this paper). That said, I leave these alternatives aside to focus solely on how a proponent of Lewisian PR could endorse quidditism. The issue of how quidditism relates to different accounts of what possibilities exist is interesting on its own, but its analysis has to be postponed for another occasion.
} 
assumption that PR is true and that properties and their respective qualitative features can be freely recombined. Yet in order to achieve that, PR has to be extended to apply to properties (Lewis 2009: p. 209). This, however, seems to be prima facie problematic for a Lewisian. All interpreters of Lewisian PR seem to agree that PR is only an extensional principle that recombines duplicates of individuals, and that we treat individuals as genuine parts of possible worlds. Now, following Lewis's nominalism, if properties are transworld sets of individuals, how should we understand the Rquidditistic claim that properties can be freely recombined? If properties are transworld sets of individuals, then their identities depend on a distribution of individuals in the relevant possible worlds. As a consequence, properties so understood are not just usual parts of possible worlds (besides individuals) that can be taken away and recombined. Moreover, does it even make sense to recombine a transworld set of individuals across different possible worlds? In contrast to that, within an Armstrongian combinatorialism, where properties are understood as real universals, we can treat them, rather straightforwardly, as genuine elements of the actual world and take at face value claims about their recombination. Does a Lewisian have any way of accommodating her view of PR to allow for the recombination of properties (understood as transworld sets of individuals) without giving up nominalism?

Recently, Curtis (2016) argued that despite this prima facie difficulty, Lewisian PR can be accommodated to allow for a recombination of properties conceived as transworld sets of individuals. A simplified version of his argument runs as follows.

Suppose there is a simple possible world $W_{1}$ in which only two fundamental properties $F$ and $G$ exist, where $F$ occupies property role $\Phi$, and $G$ occupies property role $\Psi$. Moreover, assume that in $W_{1}$ there are two individuals $a$ and $b$, where $a$ is $F$ while $b$ is $G$. Also assume that individuals $a$ and $b$ are related by some spatio-temporal relation $R$. Thus, a sequence of $\langle a, b\rangle$ satisfies $R$ and constitutes a maximal spatiotemporal sum. Now, suppose that there is a possible world $W_{2}$, in which duplicates of $a$ and $b$ exist (call them $a^{*}$ and $b^{*}$ ), are also related by a spatio-temporal relation $R$, but are being recombined. We then receive a sequence $\left\langle b^{*}, a^{*}\right\rangle$, satisfying $R$ and constituting a maximal spatio-temporal sum. As a result, sequence $\left\langle b^{*}, a^{*}\right\rangle$ is spatio-temporally isomorphic with $\langle a, b\rangle$. Now, if facts concerning which property roles exist at which a possible world supervenes on spatio-temporal arrangements of individuals at a relevant world (under the assumption of Humean supervenience), and if $<b^{*}, a^{*}>$ and $<a, b>$ are spatio-temporally isomorphic, then $W_{1}$ and $W_{2}$ contain that same distribution of property roles, namely, $\langle\Phi, \Psi>$. Now, recall that, for Lewis, $x$ being a duplicate of $y$ is for $x$ to share all fundamental properties with $y$. Therefore, permuted duplicates swap their places together with their respective properties. Thus, $W_{2}$ has a structure $<b^{*}$ is $G, a^{*}$ is $F>$, while $W_{1}$ has a structure $<a$ is $F, b$ is $G>$. At this point, $W_{1}$ and $W_{2}$ are qualitatively and structurally indiscernible (their structures are isomorphic). However, an important difference between $W_{1}$ and $W_{2}$ is that $F$ has $\Psi$, and $G$ has $\Phi$ in $W_{2}$, while $F$ has $\Phi$, and $G$ has $\Psi$ in $W_{1}$. This holds because even though properties $F$ and $G$ swap places with their duplicates $a^{*}$ and $b^{*}$, which means duplicates of $a$ and $b$ instantiate the same respective fundamental properties, a distribution $<\Phi, \Psi>$ of property roles stays unchanged under the permutation of duplicates because they supervene on the spatio-temporal arrangement of individuals, which in turn were claimed to be isomorphic across $W_{1}$ and $W_{2}$. 
In light of such remarks, Curtis then concludes that it is possible (within a purely Lewisian metaphysical framework) to extend PR to properties and to provide grounds for quidditistic differences between worlds required to establish R-quidditism.

\section{Critique}

In this section, I shall argue that a proponent of Lewisian PR faces difficulties when extending it to properties. Moreover, even if she would somehow manage to overcome them, there are further issues concerning Humean supervenience that make the Lewisian unable to endorse R-quidditism. I conclude that without major modifications of her view (e.g., dropping a commitment to Humean supervenience and/or endorsing some kind of I-quidditism), a Lewisian cannot endorse R-quidditism at all.

\subsection{An Argument against Curtis's Solution}

I argue that a way Curtis accommodates Lewisian PR to quidditism is problematic. In order for his solution to work, the relevant spatio-temporal relation $R$ has to be conceived as a transworld entity. Only under such an assumption can it be inferred that $W_{1}$ and $W_{2}$ are isomorphic. Curtis assumes that to be the case when he argues that the same relation $R$ is satisfied both by a sequence $\langle a, b\rangle$ at $W_{1}$ and by a sequence of their counterparts $<b^{*}, a^{*}>$ at $W_{2}$. However, why cannot recombination affect spatiotemporal relations as well? If we can freely recombine individuals and properties (if Curtis is correct in extending PR to properties), why should not we be able to freely recombine relations (especially natural relations such as spatio-temporal ones) with their qualitative profiles? It seems uncontroversial to assume that spatio-temporal relations (similarly as properties) have associated qualitative profiles that determine what spatio-temporal relations do in a given possible world. ${ }^{11}$ Now, by using PR, we are allowed to freely recombine spatio-temporal relations with their qualitative profiles. As a result, we receive worlds that can be different with respect to which spatiotemporal relation plays which qualitative role. Such possibilities seem to have been anticipated by Lewis (Lewis 1986: p. 75-76), as he claimed that there might be possible worlds with only analogical spatio-temporal relations that are similar to actual spatiotemporal relations but that do not play exactly the same roles as actual spatio-temporal relations.

If the recombination of relations and their qualitative roles is allowed, then the spatio-temporal relation $R$ of $\langle a, b\rangle$ at $W_{1}$ plays an identical qualitative role in some worlds but not others. However, there is no argument in Curtis's reasoning that would guarantee $R$ plays the same qualitative role in $W_{2}$ (i.e., that $R$ from $W_{1}$ is transworld identical to $R$ in $W_{2}$ ). Without such an argument, it is indeterminate whether relation $R$ holds both at $W_{1}$ and $W_{2}$, or whether the same qualitative profile existing at $W_{1}$ and $W_{2}$ is satisfied by two numerically distinct relations, $R$ and $R^{*}$. In order for Curtis's solution

\footnotetext{
${ }^{11}$ This analogy between relations and properties is supported by the fact that one can define relations in terms of properties (by using a concept of relational property) or define properties in terms of relations (by claiming that properties are just 0 -place relations).
} 
to work in a systematic manner, it has to be supplemented to ensure relation $R$ itself (not its qualitative profile) is transworld identical in $W_{1}$ and $W_{2}$.

Moreover, Curtis's extension of Lewisian PR to properties relies on Humean supervenience being true at relevant worlds. However, Lewis has explicitly stated that Humean supervenience is only contingently true (Lewis 1986, chapter 1.2). Thus, there are possible worlds in which Humean supervenience does not hold. Whether PR can be extended to properties in some possible worlds depends on whether Humean supervenience is true in relevant worlds, but if there are possible worlds where Humean supervenience is false, it follows with respect to Lewisian PR that there are possible worlds that cannot be extended to properties. If so, there are possible worlds with elements (properties) that cannot be recombined by using Lewisian PR. However, if Lewisian PR is meant to be a systematic and general principle governing possibilities that does not leave any gaps in logical space, it should also be applicable to elements of worlds in which Humean supervenience is false (e.g., worlds in which phenomenal properties such as qualia do not supervene on a distribution of local qualities). If Lewisian PR does not apply to properties in such possible worlds, it leaves gaps in logical space. The easiest way to avoid such a consequence would be to deny the dependence of Lewisian PR on Humean supervenience. This, however, entails giving up the reductive spirit of Lewisian metaphysics. Another option is to give up quidditism. No matter which option we choose, there is no cheap way of extending Lewisian PR to properties.

\subsection{Humean Supervenience and Quidditism}

Secondly, even we if ignore the problem with Lewisian PR discussed above, I argue that there is no place for I-quidditism within an orthodox Lewisian framework for the same reason that there is no place for haecceitism. ${ }^{12}$ This reason is Humean supervenience. Lewis explicitly claimed (1986: p. 232) that the main reason for his anti-haecceitism was his belief in Humean supervenience. I argue that the same reasoning can be extended to I-quidditism. A Lewisian might be fine with that since she aims to endorse R-quidditism, rather than I-quidditism. However, if establishing some variant of I-quidditism is a necessary condition for endorsing R-quidditism, ${ }^{13}$ a Lewisian cannot be an R-quidditist as well.

According to Humean supervenience, there is a distribution of local qualities (fundamental properties), and everything else supervenes on them. This runs against haecceitism, because if Humean supervenience is true, there cannot be differences in how possible worlds represent de re without differences in the distribution of local qualities in the relevant possible worlds. As Lewis famously claimed, what is true de re about a given pair of possible worlds supervenes on the qualitative character of those worlds (1986: p. 221), where the qualitative character of a given world is identified with a distribution of fundamental qualities.

\footnotetext{
$\overline{12}$ This is true only if haecceitism is understood as a view that representation de re of possible worlds does not supervene on their qualitative character. Such view however should not be confused with a view that there are haecceitistic possibilities for individuals, e.g. that Socrates could have been a poached egg or his twin brother (if he would had one). Lewis allows for haecceitistic possibilities for individuals but denies haecceitism for worlds. He explicitly called such position as cheap haecceitism (Lewis 1986: p. 228).

${ }^{13}$ For more details on this, see sections 3 and 5.3 of this paper.
} 
I claim that this reasoning can be extended to I-quidditism as well. If I-quidditism were true, it would entail that some things do not supervene on the qualitative character of a given world because quidditistic facts (that is, facts about the identities of properties) are also facts independent from qualitative facts characterising a given world. However, if Humean supervenience is true, it follows that quidditistic facts have to supervene (as everything else does) on the distribution of local qualities. This falsifies I-quidditism. Now, if I-quidditism is a necessary condition for establishing Rquidditism, then by denying I-quidditism, one is unable to establish R-quidditism. Therefore, by accepting Humean supervenience, one is forced to accept some kind of structuralism about the individuation of properties or a similar view (e.g., dispositionalism). These views, however, preclude R-quidditism.

As a result, it seems that Humean supervenience and quidditism (in both mentioned variants) cannot be held together. If so, should a proponent of Lewisian PR give up Humean supervenience or quidditism? Judging from the Lewisian perspective, it seems that it would be preferable to give up quidditism because much less depends on quidditism than on Humean supervenience. To be more specific, restricting PR such that it precludes quidditistic possibilities for individuals (or properties) is less problematic than giving up Humean supervenience, which is essential for the whole of Lewisian metaphysics.

In response, one might claim that quidditism cannot be dropped so easily because endorsing quidditism was very important for Lewis. More specifically, it was a crucial premise (coupled with PR as another premise) in a permutation argument for Ramseyan humility, an epistemological view according to which we lack knowledge about the identities of (fundamental) properties. ${ }^{14}$ If my argument is correct, the critic would say, it would follow that Lewis cannot establish Ramseyan humility.

My response is this: There is an easy way for a Lewisian to preserve a belief in Ramseyan humility even without endorsing quidditism. I argue that Ramseyan humility (or a view very close to it) can be motivated even within a purely structuralist view on the identities of properties (and relations). Even if we assume that the identities of properties can be fully explained by their qualitative property roles, and if some or most of qualitative roles are knowable (in principle) by us, it does not follow that we know the identities of properties. This is so because in order to know the identities of properties, we would have to know the complete (past, present, and future) pattern of distribution of causal and nomological roles in a given possible world. Yet it seems either impossible or very difficult to achieve this. Thus, Ramseyan humility (or something very similar to it) is necessarily true or true most of the time. Either way, even within a structuralist framework, it is possible to preserve a view that we lack important knowledge about the identities of properties. Thus, my criticism of extending PR does not entail the falsity of Ramseyan humility. (The same reasoning can be reiterated for a dispositionalist account of the identities of properties.)

Still, someone might argue that R-quidditism can be motivated independently of Iquidditism. In such case, it would be possible to simultaneously maintain Humean supervenience and R-quidditism without commitment to I-quidditism. This might be an

\footnotetext{
14 The original formulation of the permutation argument can be found in Lewis (2009). For a detailed discussion of it see Leuenberger (2010), Locke (2012), and Curtis (2016).
} 
attempt at providing a cheap substitute for R-quidditism that would not presuppose any account of the individuation of properties.

However, as I argued in section 3, there are two strong arguments supporting the claim that R-quidditism cannot be motivated independently from some variant of Iquidditism. Let me elaborate them in more detail.

A first argument is that having quidditistic possibilities without a quidditistic account of the identities of properties is problematic, because without I-quidditism, a Lewisian based solely on PR cannot provide enough possible worlds to characterise Rquidditism. If I-quidditism is false, it entails that qualitative roles of properties are essential for them. As a result, PR has to be constrained by some essentialistic principles concerning the modal features of properties that preclude their free recombination with their qualitative profiles. However, if such constraints are not meant to be primitive, a Lewisian owes us an account of how properties are individuated instead. Moreover, a Lewisian needs an account of the individuation of properties that allows for R-quidditism and is distinct from any variant of I-quidditism. It is unclear how such account would go. It seems that the only alternative is some kind of structuralism (properties are individuated by their causal or nomological features) or dispositionalism (properties are sets of dispositions). ${ }^{15}$ However, accepting these kinds of views precludes R-quidditism, which would be an undesired consequence for a Lewisian.

A second reason against possibility of cheap R-quidditism is quite general, and it concerns modality as such. I share a view that what possibilities there are with respect to a given domain of entities are grounded in the nature of entities in that domain. ${ }^{16}$ To claim otherwise is to endorse a controversial view that modal issues are more fundamental than first-order metaphysical (non-modal) issues about the nature of reality. Applying these remarks to the issue of properties: What possibilities there are with regard to properties depend on the nature of properties. Thus, whether R-quidditism is true depends on whether I-quidditism is true. Not the other way around.

In light of these remarks, I have two conclusions. Firstly, a Lewisian cannot accept Humean supervenience together with I-quidditism. Secondly, and she cannot endorse $\mathrm{R}$-quidditism without endorsing I-quidditism. And if endorsing I-quidditism is impossible for her (due to Humean supervenience), she cannot endorse R-quidditism either. However, even if a Lewisian would somehow reconcile Humean supervenience with Iquidditism, in a following section I argue that Humean supervenience is problematic on its own.

\subsection{Humean Supervenience and Possibilities for Non-fundamental Entities}

Independent of whether a Lewisian can accommodate PR to properties and endorse quidditism (in any introduced variant), there is a reason to believe that Humean

\footnotetext{
${ }^{15}$ For a discussion of structuralism, see the works cited in footnote 5. For an overview on a dispositionalist account of properties, see Ellis and Lierse (1994) and Bird (2007).

${ }^{16}$ This is a weaker (because grounding is not reduction) version of a view that modality can be reduced to essence. According to this view, modal concepts (e.g., possibility or necessity) for a given domain $D$ of entities are grounded in essences (or identities, if essences are conceived as individuators of the entities in question) of objects in that domain. A reductive view of modality is widely held in contemporary modal metaphysics. The most notable proponents of such approach to modality are Fine (1994), Correia (2006), Oderberg (2007), and Lowe (2008).
} 
supervenience is incompatible with Lewisian modal metaphysics. More specifically, I shall argue that Humean supervenience has trouble explaining modalities for nonfundamental entities. Such explanation either lacks generality, and thus leaves gaps in logical space, or appeals to primitive modality, which results in circularity. Both consequences are unacceptable for a proponent of a Lewisian analysis of modality.

A main ambition of Lewis's analysis of modality is to provide the extensional reduction of all intensional modal concepts, where an analysis of some modal concept counts as extensional if it does not appeal to any primitive (irreducible) modal concepts throughout the analysis. Such reduction is unproblematic in cases where possibilities concerning a supervenience base are composed solely of fundamental entities. For the purpose of the analysis, let us assume that electrons are fundamental entities and constitute a fundamental base of the actual world and accessible possible worlds. Next, consider a simple possibility that for some actually existing electron $e$ located in Europe, it is possible that $e$ could be located in Africa. A Lewisian will provide an extensional analysis of such a possibility by arguing that there is a possible world in which a duplicate of $e$ - that is, $e^{*}$, which is intrinsically the same as $e$, meaning they share all natural and intrinsic properties - is in Africa. Such an analysis can be then generalised to cover all kinds of fundamental entities. For any actually existing fundamental entity $x, x$ is possibly $F$ iff there is a possible world containing a duplicate of $x$, called $x^{*}$, that is exactly similar to $x$ and is $F$. (Of course, analogical generalisations can be formulated for other modalities.) As a result, a Lewisian has no trouble with explaining possibilities for a supervenience base.

However, as Wilson (2015: p. 150-153) has shown, a proponent of Humean supervenience cannot provide a satisfying explanation of possibilities for nonfundamental entities. Let me reconstruct her argument and relate it to our current discussion of Lewisian PR.

For the sake of argument, suppose that it is possible for some brown kangaroo to be plaid rather than brown. How could a Lewisian explain such possibility? Well, she cannot appeal to the exact similarity of the respective supervenience bases of brown kangaroos and plaid kangaroos, for these bases must differ in some important respects in order to ground differences between the appearance of kangaroos. Our Lewisian might then say that these bases have to be sufficiently similar or similar only in some respects. However, it would be hard to define sufficient similarity or relevant respects of similarity in this case, as it is unclear how the supervenience bases of the properties being brown and being plaid are similar. And even if a Lewisian would somehow explain how such supervenience bases have to be similar, such an answer would apply only to this particular case and therefore would lack generality. In order to give a general account of modality for non-fundamental entities of a given kind, one has to provide a general account of how a supervenience base of a given kind relates to a relevant kind of supervenient entities. This is something which cannot be given by a proponent of Humean supervenience. As a result, Humean supervenience would not deliver a systematic account of possibilities for non-fundamental entities. Thus, if the truth of Lewisian PR depends on Humean supervenience, PR would not provide a systematic and principled explanation of possibilities either, contrary to the initial premise.

According to Wilson (and I follow her remark here), there are only two remaining ways for a Lewisian to provide a general analysis of modalities for non-fundamental 
entities. One option is to endorse primitivism and claim that it is just a brute fact that such-and-such supervenience base gives rise to such-and-such supervenient entity. This strategy, however, explicitly involves primitive modality. Another option is to claim that "the relevant Hume-intrinsic goings-on are those serving as a basis for a possible macroentity of the type" (Wilson 2015: p. 153), which also entails irreducible possibility.

From the fact that a supervenience base requires primitive modality to explain nonfundamental entities, it follows that the whole Lewisian analysis of modality is circular. The reasoning is straightforward: If Lewisian PR is meant to give us an extensional analysis of modal concepts, if it is the case that in order to establish the truth of Lewisian PR we have to rely on Humean supervenience (what has been highlighted by Curtis), and if Humean supervenience requires primitive modality, it follows that we have to have modal concepts at our disposal prior to the characterisation of PR. Thus, the Lewisian analysis of modality based on PR is circular.

\section{Conclusion}

I have argued that Lewisian PR is incompatible with quidditism unless a Lewisian modifies some important elements of her doctrine. I presented three arguments in support of my position: First, I have shown that some recent attempt at extending Lewisian PR to properties developed in (Curtis 2016) is problematic for it presumes that PR does not apply to spatiotemporal relations. However, as I have claimed, there is no reason why PR should not be extended to fundamental relations such as spatio-temporal ones. If so, this leads to indeterminacy in his argument. Moreover, Curtis' way of extending PR to properties explicitly relies on Humean supervenience being true. However, I have argued that Humean supervenience (i) precludes I-quidditism, and if truth of some variant of I-quidditism is required for the truth of R-quidditism, Humean supervenience precludes R-quidditism, and (ii) undergenerates possibilities for non-fundamental objects, and thus, if PR is coupled with Humean supervenience, either it leaves gaps in logical space or Lewisian analysis of modality (based on PR) is circular. As a result, a Lewisian has hard choice to make: either she has to abandon Humean supervenience or give up quidditism (in both variants).

Funding This work was supported by Narodowe Centrum Nauki (Grant No. 2017/25/N/HS1/01378).

Open Access This article is licensed under a Creative Commons Attribution 4.0 International License, which permits use, sharing, adaptation, distribution and reproduction in any medium or format, as long as you give appropriate credit to the original author(s) and the source, provide a link to the Creative Commons licence, and indicate if changes were made. The images or other third party material in this article are included in the article's Creative Commons licence, unless indicated otherwise in a credit line to the material. If material is not included in the article's Creative Commons licence and your intended use is not permitted by statutory regulation or exceeds the permitted use, you will need to obtain permission directly from the copyright holder. To view a copy of this licence, visit http://creativecommons.org/licenses/by/4.0/.

\section{References}

Adams, R. M. (1979). Primitive thisness and primitive identity. The Journal of Philosophy, 76(1), 5-26.

Adams, R. M. (1981). Actualism and thisness. Synthese, 49(1), 3-41. 
Armstrong, D. M. (1989). A combinatorial theory of possibility. Cambridge: Cambridge University Press. Bird, A. (2007). Nature's metaphysics. Oxford: Oxford University Press.

Black, R. (2000). Against quidditism. Australasian Journal of Philosophy, 78(1), 87-104.

Curtis, B. L. (2016). Lewisian quidditism, humility, and diffidence. Philosophical Studies, 173(11), 30813099 .

Correia, F. (2006). Generic essence, objectual essence, and modality. Noûs, 40(4), 753-767.

Darby, G., \& Watson, D. (2010). Lewis's principle of recombination: Reply to Efird and Stoneham. Dialectica, 64(3), 435-445.

Divers, J., \& Melia, J. (2002). The analytic limit of genuine modal realism. Mind, 111(441), 15-36.

Efird, D., \& Stoneham, T. (2008). What is the principle of recombination? Dialectica, 62(4), 483-494.

Ellis, B., \& Lierse, C. (1994). Dispositional essentialism. Australasian Journal of Philosophy, 72(1), $27-45$.

Fine, K. (1994). Essence and modality. Philosophical Perspectives, 8, 1-16.

Hawthorne, J. (2001). Causal structuralism. Philosophical Perspectives, 15, 361-378.

Kment, B. (2012). Haecceitism, chance, and counterfactuals. Philosophical Review, 121(4), 573-609.

Leuenberger, S. (2010). Humility and constraints on O-language. Philosophical Studies, 149(3), 327-354.

Lewis, D. (1986). On the plurality of worlds. Oxford: Blackwell.

Lewis, D. (2009). Ramseyan humility. In D. Braddon-Mitchell \& R. Nola (Eds.), Conceptual analysis and philosophical naturalism (pp. 203-222). Cambridge: MIT Press.

Locke, D. (2012). Quidditism without quiddities. Philosophical Studies, 160(3), 345-363.

Lowe, E. J. (2008). Two notions of being: entity and essence. Royal Institute of Philosophy Supplement, 83(62), 23-48.

McDaniel, K. (2004). Modal realism with overlap. Australasian Journal of Philosophy, 82(1), 137-152.

Oderberg, D. (2007). Real essentialism. London: Routledge.

Plantinga, A. (1976). Actualism and possible worlds. Theoria, 42(1-3), 139-160.

Roca-Royes, S. (2018). Genuine modal realism, the Humean thesis and advanced modalizing. Synthese, 197, 4669-4690.

Schaffer, J. (2005). Quiddistic knowledge. Philosophical Studies, 123(1-2), 1-32.

Shoemaker, S. (1980). Causality and properties. In Time and cause (pp. 109-135). Dordrecht: Springer.

Smith, D. C. (2016). Quid quidditism est? Erkenntnis, 81(2), 237-257.

Wang, J. (2016). The nature of properties: causal essentialism and quidditism. Philosophy Compass, 11(3), $168-176$.

Wilson, J. (2010). What is Hume's dictum, and why believe it? Philosophy and Phenomenological Research, $80,595-637$.

Wilson, J. (2015). Hume's dictum and metaphysical modality. In B. Loewer \& J. Schaffer (Eds.), The Blackwell Companion to David Lewis (pp. 138-158). Oxford: Blackwell.

Publisher's Note Springer Nature remains neutral with regard to jurisdictional claims in published maps and institutional affiliations. 